\title{
A EFICÁCIA DOS PROJECTOS ESPECIAIS DE URBANISMO COMERCIAL.
}

\author{
EVIDÊNCIAS DE BRAGA
}

Pedro Guimarães ${ }^{1}$

RESUMO - Este artigo tem como objectivo analisar o processo de implementação dos programas públicos Procom e Urbcom na cidade de Braga. Estes programas foram concretizados no território através dos designados projectos especiais de urbanismo comercial, mecanismos peculiares no âmbito das intervenções de regeneração urbana das áreas comerciais em Portugal por disponibilizarem fundos integrados para a modernização dos estabelecimentos comerciais, reabilitação do espaço público e animação comercial. Para analisarmos a eficácia de ambos os projectos elaboramos 50 inquéritos a empresários que aderiram aos projectos e quatro entrevistas a stakeholders com conhecimento acerca dos mesmos. Concluímos que o processo de modernização dos estabelecimentos já estava em curso e ia efectuar-se mesmo sem a adesão aos projectos, tal como também já se encontrava a decorrer a reabilitação das ruas do centro da cidade, tendo a contribuição do Procom e Urbcom sido reduzida. As acções promocionais realizadas pela associação comercial foram efémeras e concentradas em poucos eixos comerciais, o que restringiu a sua capacidade de produzir impactos positivos. De forma geral, pelo que foi dito acima e porque não foram capazes de minimizar as ameaças externas, concluímos que ambos os projectos foram ineficazes na regeneração do tradicional centro de comércio da cidade de Braga.

Palavras-chave: Braga; Procom; Urbcom; projectos especiais de urbanismo comercial; regeneração urbana.

ABSTRACT - The EFFECTIVENESS OF THE SPECIAL PROJECTS OF COMMERCIAL URBANISM. Evidence From Braga. The aim of this article is to analyse the process of implementation of the public programmes Procom and Urbcom in the city of Braga. These programmes were implemented in the territory through the special projects of commercial urbanism, peculiar mechanisms for the urban regeneration of commercial areas in Portugal based on integrated funding for the modernization of shops, the rehabilitation of public space and commercial animation. To analyse the effectiveness of both projects we conducted 50 surveys with

Recebido: Agosto 2015. Aceite: Fevereiro 2016.

1 Investigador da Universidade de Lisboa, Instituto de Geografia e Ordenamento do Território, Centro de Estudos Geográficos, Rua Branca Edmée Marques, 1600-276, Lisboa, Portugal. E-mail: pedroguimaraes@campus.ul.pt 
entrepreneurs and four interviews with relevant stakeholders. Our findings show that the modernization of the outlets was already underway and it was going to be carried out even without adhering to the projects. In a similar process, the physical rehabilitation of the town centre was already under way. Thus, the role of the Procom and Urbcom projects was very limited. The promotional actions carried out by the Chamber of Commerce were ephemeral and concentrated in a limited number of commercial streets, which restricted their ability to produce positive impacts. Overall, due to this and the inability to minimize external threats we conclude that both projects were ineffective in the regeneration of the city centre of Braga.

Keywords: Braga; Procom; Urbcom; special projects of commercial urbanism; urban regeneration.

RESUME - L'EFFICACITÉ DES PROJETS SPÉCIAUX D'URBANISME COMMERCIAL. LE CAS DE BRAGA. Cet article anlyse le processus de mise en œuvre de programmes publics Procom e Urbcom dans la ville de Braga. Ils ont été réalisés à travers des "Projets Spéciaux d'Urbanisme Commercial", mécanismes qui, dans le cadre des interventions de renouvellement urbain des quartiers commerciaux au Portugal, présentent la particularité de fournir des fonds à la fois pour la modernisation des établissements commerciaux, pour la réhabilitation de l'espace public et pour l'animation commerciale. Afin d'analyser l'efficacité des deux projets, 50 enquêtes ont été menées auprès d’entrepreneurs ayant adhéré aux projets, ainsi que 4 entretiens auprès d'acteurs ayant connaissance de ces programmes. Les résultats montrent que le processus de modernisation des établissements était déjà en cours et qu'il allait de toute façon s'effectuer même sans adhésion aux projets. De la même manière, la réhabilitation des rues du centre-ville était déjà en cours. La contribution des projets Procom et Urbcom apparaît donc réduite. Les actions de promotion réalisées par l'association commerciale ont été éphémères et se sont concentrées sur un nombre réduit d'axes commerciaux, ce qui a diminué leur capacité à produire des impacts positifs. D’une manière générale, pour les raisons mentionnées plus haut et par leur incapacité à minimiser les menaces externes, il ressort en conclusion que les deux projets ont été inefficaces dans la régénération du centre-ville de Braga.

Mots clés: Braga; Procom; Urbcom; projets spéciaux d’urbanisme commercial; régénération urbaine.

\section{INTRODUÇÃO}

Face à forte relação entre o comércio e os centros urbanos, algumas transformações naquele sector provocaram impactos significativos na estrutura hierárquica dos centros de comércio das cidades (Barata-Salgueiro \& Erkip, 2014; Cachinho, 2014). Estas mudanças acentuaram-se desde meados do século passado com o aparecimento de novos formatos comerciais e a sua localização fora dos tradicionais centros de comércio, o desenvolvimento de novas técnicas de venda e o alargamento dos horários de funcionamento, colocando em causa a viabilidade e a vitalidade dos centros das cidades e do seu tecido comercial (Balsas, 2007; Instone \& Roberts, 2006; Thomas \& Bromley, 2003). Num pro- 
cesso que partilha algumas semelhanças com o que se verificou na maioria dos países da Europa Ocidental, em Portugal estas transformações decorreram um pouco mais tardiamente (Guimarães, 2013), tendo feito sentir-se de forma mais vincada já durante as décadas de 1980 e 1990.

Salientando a importância do antigo centro das cidades e do seu aparelho comercial, o sector público tem reagido através de um conjunto de medidas que usualmente se classifica como fazendo parte do planeamento comercial, entendido como a regulação levada a cabo pelo Governo sobre o sistema comercial (Guy, 2007). Em Portugal, a par da introdução da obrigatoriedade da autorização prévia para os estabelecimentos e conjuntos comerciais de maior dimensão, destacam-se os programas de urbanismo comercial, disponibilizando fundos para a modernização dos estabelecimentos comerciais, para a reabilitação do espaço público das áreas intervencionadas e para a elaboração de acções de animação e promoção comercial. Designados por Procom e Urbcom, foram considerados relevantes na regeneração de diversos centros de comércio das cidades em Portugal, sobretudo pela disponibilidade financeira e pela considerável adesão de empresas, câmaras municipais e associações comerciais. Neste artigo vamos analisar o processo de implementação dos projectos Procom e Urbcom, executados na cidade de Braga no final da década de 1990 e década de 2000, respectivamente. Para tal, recorreremos ao conceito da eficácia, tal como descrito no guia Evalsed da Comissão Europeia (2008), verificando se os objectivos foram atingidos e se as soluções utilizadas foram as adequadas. Entendemos que aqueles projectos se enquadram na definição de regeneração urbana tal como entendida por Roberts (2000: 17): comprehensive and integrated vision and action which leads to the resolution of urban problems and which seeks to bring about a lasting improvement in the economic, physical, social and environmental condition of an area that has been subject to change. Também iremos aludir ao conceito de reabilitação, neste caso com um carácter mais restricto e para nos referirmos às intervenções que apenas tiveram como objectivo a intervenção física no território.

Embora já existam alguns estudos nacionais que dedicaram alguma atenção aos programas de urbanismo comercial [Balsas, (1997, 1999, 2002); Fernandes, et al., (2000); Fernandes, (2012)], nunca se procedeu a uma avaliação dos impactos que os seus projectos provocaram nas áreas intervencionadas. Apesar da especificidade daqueles programas, esta situação não é exclusiva do contexto nacional. Também Tyler et al. (2013) e Findlay e Sparks (2009) reconheceram que existe uma lacuna de bibliografia que foque os impactos dos vários projectos de regeneração urbana. Deste modo, a pesquisa realizada para este artigo pretendeu dar um contributo para suprir aquela lacuna e pode ser do interesse para dois conjuntos de leitores. Por um lado, para os investigadores que se possam debruçar sobre as experiências desenvolvidas em Portugal ou que encontrem nos casos de estudo desenvolvidos neste artigo um reflexo de experiências desenvolvidas em outros países. Por outro lado, para os decisores nacionais, representantes de autarquias e de associações comerciais e outros stakeholders. Apesar destes projectos já terem terminado na década de 2000, de facto alguns programas públicos com um cariz próximo daqueles que analisamos neste artigo continuam a ser implementados actualmente. Desta 
forma, é possível aprender com a experiência dos projectos já terminados e que analisamos neste artigo. Ao assumirmos esta postura aproximamo-nos de Alexander (2006) que defende que o objectivo da avaliação ex-post é aprender a partir da experiência, na medida em que as conclusões obtidas podem ser lições úteis para o futuro. Ademais, Greene (2009) realça a importância do exercício de avaliação como um mecanismo para informar os vários stakeholders se os programas para os quais contribuíram conseguiram atingir os impactos desejados.

\section{O PLANEAMENTO COMERCIAL}

O planeamento comercial é uma das vertentes do planeamento territorial. Contudo, importa distingui-lo do urbanismo comercial, por vezes confundidos e utilizados como sinónimo. Com este propósito utilizamos a definição de Mérenne-Schoumaker e Browet (1988) que o considerou como o campo do urbanismo que se debruça sobre o sector comercial, na busca das localizações mais adequadas, com os aspectos arquitectónicos e funcionais, com os mecanismos de valorização das funções de animação e centralidade do comércio e com a determinação de critérios para a avaliação da necessidade de espaços comerciais. Ainda que posteriormente Cachinho (1992) tenha alargado aquela definição, consideramos que o planeamento comercial envolve outras valências, aproximando-o do conceito de Guy (2007: 1) que considerou que o planeamento comercial (...) is usually described as a part of the process of government regulation of the retail system. A este propósito entendemos haver um paralelismo com a distinção entre ordenamento do território e o planeamento tal como efectuada por Ferrão (2014). Este autor considerou este último conceito como integrador do ordenamento do território e, simultaneamente, transcendente. Assim, por considerarmos que o urbanismo comercial tal como entendido anteriormente é redutor, adoptamos o conceito de planeamento comercial pela sua abrangência. Baseado no trabalho dos autores referidos, Guimarães (2015) definiu o planeamento comercial como a regulação efectuada sobre o sector comercial onde deve estar presente, directa ou indirectamente, a estratégia de desenvolvimento do sector comercial em determinado contexto nacional. Não obstante, o conceito de urbanismo comercial mantém a sua validade e adequa-se às intervenções realizadas no âmbito do Procom e Urbcom.

Embora ao longo das últimas décadas tenha sofrido algumas variações significativas (Davies, 2004), já na década de 70 Dawson (1979) tinha distinguido duas abordagens nas políticas comerciais que ainda se mantêm relativamente inalteradas. A primeira procura a eficiência do sector, através da competição entre empresas, excluindo aquelas que, num quadro competitivo, sejam menos capazes. A segunda foca a equidade, exige uma maior participação do sector público, com o intuito de permitir o abastecimento da totalidade da população, independentemente da sua localização. Estas diferentes abordagens não decorrem isoladamente, o que leva a que num determinado momento os objectivos do planeamento comercial se assumam como contraditórios. De facto, tal como Seip e 
Voogd (1998, in Gorter, et al., 2003) constataram, dois distintos objectivos coexistem simultaneamente: por um lado, a procura do crescimento e renovação comercial e, por outro lado, a manutenção da função comercial do centro da cidade. A plena concretização do primeiro objectivo implica uma maior desregulamentação enquanto a obtenção do segundo exige uma regulação mais forte.

Ainda que tomando em consideração os dois objectivos referidos e reconhecendo as vantagens inerentes à modernização do sector, mas também a necessidade de abastecer a totalidade da população (Davies, 1995), na Europa Ocidental, a opção por abordagens mais ou menos restritivas tem variado no tempo e consoante o país (Guy, 1998; Howe, 2003). Embora nunca assumindo posições extremadas, de forma geral, esta variação tem sido visível em diferentes países, tal como a Holanda (Evers, 2002; Spierings, 2006), Grã-Bretanha (Guy, 2007), Suécia (Franzén, 2004; Karrholm \& Nylund, 2011) e Dinamarca (Sorensen, 2004).

Considerando os diferentes objectivos, tem-se dado preferência a soluções intermédias, ainda que com variações. Deste modo, tem-se optado por não restringir totalmente a modernização do sector comercial, através de novos formatos e localizações e, simultaneamente, têm-se introduzido um conjunto de medidas de discriminação positiva do antigo centro das cidades e do seu aparelho comercial, sobretudo aquele constituído por empresas de menor dimensão (Guimarães, 2015). No primeiro caso destacam-se algumas medidas e instrumentos, como a Lei Royer em França (Colla, 2003), as políticas PDV e GDV na Holanda (Spierings, 2006) ou a política do Town Centre First no Reino Unido (Guy, 2007). No caso das medidas de discriminação positiva para o centro das cidades e o seu comércio, o destaque tem sido dado às estruturas de town centre management já difundidas por um conjunto alargado de países e, mais recentemente, os Business Improvement Districts ${ }^{\mathrm{i}}$ que, após o aparecimento na América do Norte, têm vindo a adquirir um papel de relevo, em especial no Reino Unido.

\section{MATERIAL E MÉTODOS}

Os programas de urbanismo comercial executados em Portugal enquadram-se no conjunto de medidas de discriminação positiva dos centros das cidades. A utilização de um caso de estudo permitiu aprofundar o conhecimento acerca do processo de implantação dos projectos especiais de urbanismo comercial. Escolhemos Braga por ser uma cidade marcada pela relevância do seu principal centro. O projecto Procom implementado nesta cidade, usualmente apelidada por "capital do comércio", foi um dos que obteve uma taxa de adesão mais elevada (DGAE, 2010). Considerando que na grande maioria das cidades apenas se concretizou um projecto de um dos dois programas de urbanismo comercial, Braga foi uma das poucas onde foi executado um projecto Procom e um outro no âmbito do Urbcom (as restantes cidades em que tal sucedeu são: Coimbra, Guimarães, Lisboa e Póvoa de Varzim). Assim, a escolha da cidade de Braga como caso de estudo permitiu analisar os projectos dos dois programas. 
A hipótese definida para esta investigação parte do argumento que os projectos implantados permitiram a modernização dos estabelecimentos comerciais, a reabilitação do espaço público da área de intervenção e a realização de acções promocionais, embora a eficácia de intervenção tenha ficado circunscrita ao período de execução dos projectos. Adoptamos o conceito de eficácia tal como enquadrado pela Comissão Europeia no Guia Evalsed (fig. 1). Ao contrário dos outros conceitos, a abrangência do conceito de eficácia facilita a análise de todo o processo de implementação dos projectos, desde a fase inicial, onde se delimitam os problemas que se pretendem colmatar, passando pelos inputs e outputs, onde se analisa o montante financeiro disponibilizado, as empresas aderentes e suas intervenções, até à fase final em que se analisam os impactos que os projectos provocaram na área intervencionada.

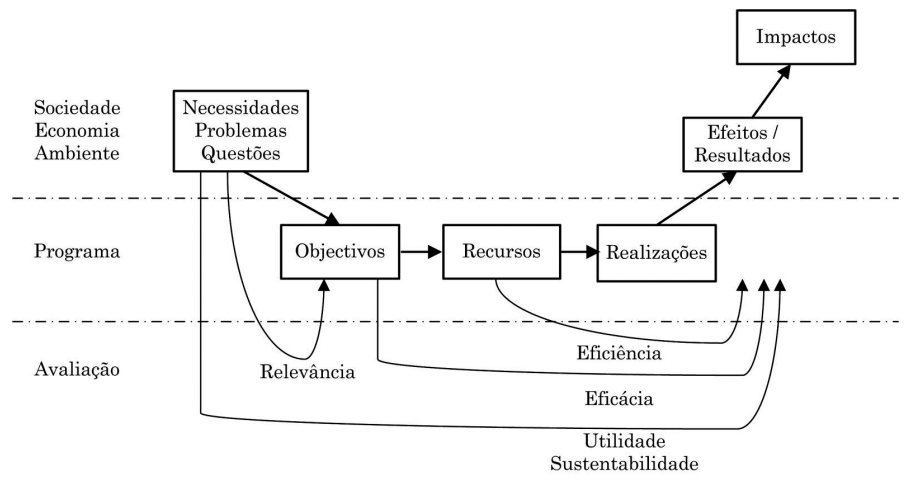

Fig. 1 - Esquema conceptual para a avaliação de programas.

Fig. 1 - Conceptual framework for programmes evaluation.

Fonte: Comissão Europeia (2008) (baseado)

Durante Março de 2014 foram realizados 50 inquéritos a empresários, cujos estabelecimentos aderiram ao Procom e/ou Urbcom. Como alguns empresários participaram nos projectos com mais do que um estabelecimento, estes inquéritos correspondem a 61 e 10 estabelecimentos aderentes ao Procom e Urbcom e a 36,1\% e 52,6\% do total de estabelecimentos apoiados, respectivamente. No caso da análise dos impactos da intervenção analisada no quadro VI, apenas nos iremos centrar no projecto Procom porque somente dois empresários aderentes ao Urbcom conseguiram dar-nos informação acerca dos impactos que o projecto provocou no território. De forma complementar foram entrevistados quatro responsáveis das seguintes instituições: Direcção-Geral das Actividades Económicas (DGAE), enquanto entidade responsável pela aprovação e monitorização dos diversos projectos implantados a nível nacional; Confederação do Comércio e Serviços de Portugal (CCP), na qualidade de estrutura representativa das associações comerciais a nível nacional; Associação Comercial de Braga; e Câmara Municipal de Braga. Parte da informação recolhida destas entrevistas foi colocada ao longo do texto como citação, tendo o nome do entrevistado sido excluído para salvaguardar a sua identidade. Estas citações distinguem-se das demais pela designação "entrevista", sendo que o número atribuído corresponde ao da instituição representada pelo entrevistado tal como apresentado no quadro I. 
Quadro I - Lista de entidades entrevistadas e data da sua realização.

Table I - List of entities interviewed and date of the meeting.

\begin{tabular}{clc}
\hline No da entrevista & \multicolumn{1}{c}{ Entidade } & Data de realização \\
\hline 1 & Direcção-Geral das Actividades Económicas & $10-12-2014$ \\
2 & Confederação do Comércio e Serviços de Portugal & $26-06-2014$ \\
3 & Câmara Municipal de Braga & $20-03-2014$ \\
4 & Associação Comercial de Braga & $04-04-2014$ \\
\hline
\end{tabular}

\section{O PLANEAMENTO COMERCIAL EM PORTUGAL}

O planeamento comercial em Portugal também se tem caracterizado pelas variações nas políticas de controlo do sector comercial (Fernandes \& Chamusca, 2014). Em parte, esta semelhança deve-se à transposição para o contexto nacional de algumas políticas e instrumentos implantados em outros países, pois, tal como Pereira et al. (2002) assume, algumas políticas adoptadas em Portugal foram imitadas do modelo Francês, por influência da Lei Royer e restantes diplomas legais. Foi com base naquela lei que em 1989 surgiu a primeira medida moderna enquadrável no planeamento comercial em Portugal, com a introdução da obrigatoriedade de autorização prévia para a implantação de grandes superfícies comerciais (Barata-Salgueiro, 1996). No entanto, para Barata-Salgueiro (1995), por via do carácter efémero e da inexistência de ligação entre a legislação que regulava o comércio e a que regulava o planeamento do território, não se podia afirmar categoricamente que o planeamento comercial tenha existido em Portugal até meados da década de 1990. Esta opinião foi corroborada por Fernandes et al. (2000), para quem, no início do novo milénio, não existia uma política para o comércio. Tal como em outros países da Europa Ocidental (Davies, 1995), a regulação dos horários de funcionamento também foi utilizada neste período para controlar o sector. Em 1995, a introdução de limitações ao horário de funcionamento das grandes superfícies comerciais contínuas aos Domingos pretendeu discriminar negativamente aqueles estabelecimentos, limitando o número de horas em que podiam estar abertos. A introdução destas medidas restritivas acaba por contrariar a tendência então vigente no Norte da Europa. Segundo (Fernandes, 1994:105) nos anos 80 e na primeira metade dos anos 90 (...) penetra no ordenamento a filosofia liberal desregulamentadora (no Norte da Europa e no Reino Unido em particular) que contribuiu para a proliferação de grandes unidades e complexos comerciais.

A par da introdução destas medidas, o Governo Português desenvolveu um conjunto de programas de apoio ao comércio, sobretudo o de pequena dimensão, com o objectivo de facilitar a modernização do tecido comercial mais antiquado que, de forma mais acentuada, tinha sentido o impacto das novas formas de comércio e que tinha perdido uma significativa quota de mercado. O primeiro programa foi o Simc - Sistema de incentivos à modernização do comércio - criado em 1991 e cujo foco se centrou em exclusivo na introdução de processos inovadores nos estabelecimentos comerciais. Em 1994, consciente de que a intervenção isolada não havia trazido grandes benefícios para a modernização do aparelho comercial dito tradicional, foi criado um novo programa. Denominado 
por Procom - Programa de apoio à modernização do comércio - a génese deste programa está no urbanismo comercial praticado em França (entrevista 1). Para além dos fundos para a modernização dos estabelecimentos comerciais, foram disponibilizadas verbas para a reabilitação do espaço público e para a execução de um plano de promoção e animação comercial das áreas intervencionadas, dando origem aos projectos especiais de urbanismo comercial e concretizando desta forma um novo modelo de regeneração urbana que caracterizou a intervenção nas áreas tradicionais de comércio em Portugal durante mais de uma década. O carácter integrador desta intervenção aplicada em Portugal foi ainda acentuado ao fazer depender as verbas disponíveis para a reabilitação do espaço púbico e para as acções promocionais do número de estabelecimentos aderentes ao respectivo projecto. Com origem em verbas europeias através do segundo Quadro Comunitário de Apoio (QCA II), este programa despoletou grande interesse junto dos empresários, das associações comerciais e das câmaras municipais. Com o fim do QCA II no final da década de 1990, sentiu-se a necessidade de dar sequência ao Procom. Assim, ancorado no novo QCA (III), em 2000 foi regulamentado o Urbcom - Sistema de incentivos a projectos de urbanismo comercial. Os princípios e tipologias de intervenção foram semelhantes aos do programa que o precedeu. No entanto, atribui-se ao Urbcom uma menor relevância por ter tido uma dotação orçamental bastante mais reduzida, o que resultou em taxas de adesão muito inferiores (entrevista 1).

De forma geral, a nível nacional foram investidos mais de 634 milhões de euros no Procom (quadro II), cuja maior fatia se deveu ao investimento realizado pelas empresas aderentes, num total de 8114 estabelecimentos intervencionados. O investimento na reabilitação urbana realizado pelas autarquias ascendeu a 86 milhões de euros e as associações comerciais investiram 28 milhões de euros nas acções promocionais. O incentivo atribuído a fundo perdido foi cerca de $50 \%$ dos valores investidos, sendo superior no caso das associações comerciais porque foram estas que ficaram encarregues de elaborar os estudos que deram origem aos diferentes projectos, designados por estudos globais.

Quadro II - Investimento realizado em Portugal no âmbito dos programas Procom e Urbcom, em euros.

Table II - Investment made in Portugal under the Procom and Urbcom programmes, in euros.

\begin{tabular}{lrrr}
\hline \multirow{2}{*}{ Investimento realizado por tipo de instituição, em $€$} & \multicolumn{2}{c}{ Programa } & \multirow{2}{*}{ Total } \\
\cline { 2 - 3 } & Procom & Urbcom & \\
\hline Empresas & 519293467 & 9803106 & 529096573 \\
Autarquias & 86880763 & 1344116 & 88224879 \\
Associações comerciais & 28197191 & 1531114 & 29728305 \\
\hline Total & 634371421 & 12678336 & 647049757 \\
\hline
\end{tabular}

Fonte: elaboração própria a partir de dados da DGAE (2010)

Durante a vigência do Urbcom o valor investido foi significativamente inferior, por via da menor disponibilidade financeira deste programa. Apesar desta diminuição, o Governo tentou apoiar o maior número possível de projectos. Para tal, baixou de forma 
clara a percentagem do incentivo (para as empresas), passando de um máximo de 66,6\% no Procom para $45 \%$ no Urbcom, o que levou a que empresários, associações comerciais e autarquias tivessem tido relutância em aderir ao programa (entrevista 2). Consequentemente, apenas 294 estabelecimentos aderiram a este programa a nível nacional, face aos 8114 que aderiram ao Procom.

De seguida iremos analisar o processo de implementação dos projectos especiais de urbanismo comercial dos programas Procom e Urbcom na cidade de Braga e analisar quais os impactos que produziram.

\section{CASO DE ESTUDO: BRAGA}

A cidade de Braga é reconhecida a nível nacional pelo dinamismo do seu tecido comercial, adoptando nas suas estratégias promocionais a designação de "capital do comércio" (Guimarães, 2014). É ainda actualmente uma cidade caracterizada pela relevância do seu centro enquanto destino de comércio e lazer, aspecto ainda mais marcado em meados da década de 1990, quando começou a ser pensado o projecto Procom. Naquele período, os principais problemas eram de cariz interno e estavam relacionados com a antiguidade do aparelho comercial, quer do espaço físico, quer das técnicas de venda e também com a fraca formação profissional dos trabalhadores e empresários do sector (Câmara Municipal de Braga, 1997).

A implantação do Procom, assim como o do Urbcom fez-se na sua área central, embora o primeiro projecto tivesse abrangido as principais ruas comerciais da cidade. Inicialmente composta por nove ruas, a área de intervenção foi alargada para um total de 22 ruas, estando as restantes treze (fig. 2) incluídas na área de intervenção do Urbcom.

$\mathrm{Na}$ altura da candidatura ao projecto Procom, estavam a verificar-se algumas alterações de relevo nesta cidade. No seguimento da criação em 1985 do Gabinete Técnico Local e em 1991 da Divisão de Renovação Urbana, o centro da cidade já estava a ser intervencionado, limitando um conjunto alargado de ruas à circulação pedonal (entrevista 3).

Foi ainda neste período que tanto a cidade de Braga como o seu aparelho comercial conheceram algumas transformações importantes. Uma face visível desta mudança foi o aparecimento de um novo tecido comercial que surgiu na consequência da expansão da cidade que se efectuou pela construção de novas urbanizações, sobretudo a que se localizou no Vale de Lamaçães. A cidade de Braga já possuía um conjunto significativo de centros comerciais, ainda que fossem na sua maioria condomínios comerciais sem gestão profissional e localizados em grande número no centro da cidade, plenamente enquadrados na malha urbana (Guimarães, 2015). No final da década esta situação altera-se com a inauguração dos centros comerciais Minho Center, em 1997, e do BragaParque, em 1999, ambos com uma localização periférica face ao centro da cidade. Por último, destaca-se a inauguração da auto-estrada ${ }^{\circ} 3$ que permitiu a rápida ligação entre as cidades do Porto e Braga no final da década de 1990, o que fez com que o tecido comercial de maior dimensão existente no Porto se tornasse uma ameaça superior para o existente em Braga 
(Associação Comercial de Braga, 1995). É neste contexto que surge e é executado o projecto Procom Braga, ao qual se associou até ao presente uma imagem de sucesso na regeneração do centro da cidade e do comércio existente (entrevista 2). Não obstante, apesar das mudanças serem notórias e relevantes, no final da década de 1990, aquando da execução do projecto Procom, o centro da cidade ainda era o principal destino comercial da cidade (Associação Comercial de Braga, 1995). Assim, este projecto assumiu um carácter essencialmente pró-activo e teve como objectivo reforçar a centralidade comercial desta área.

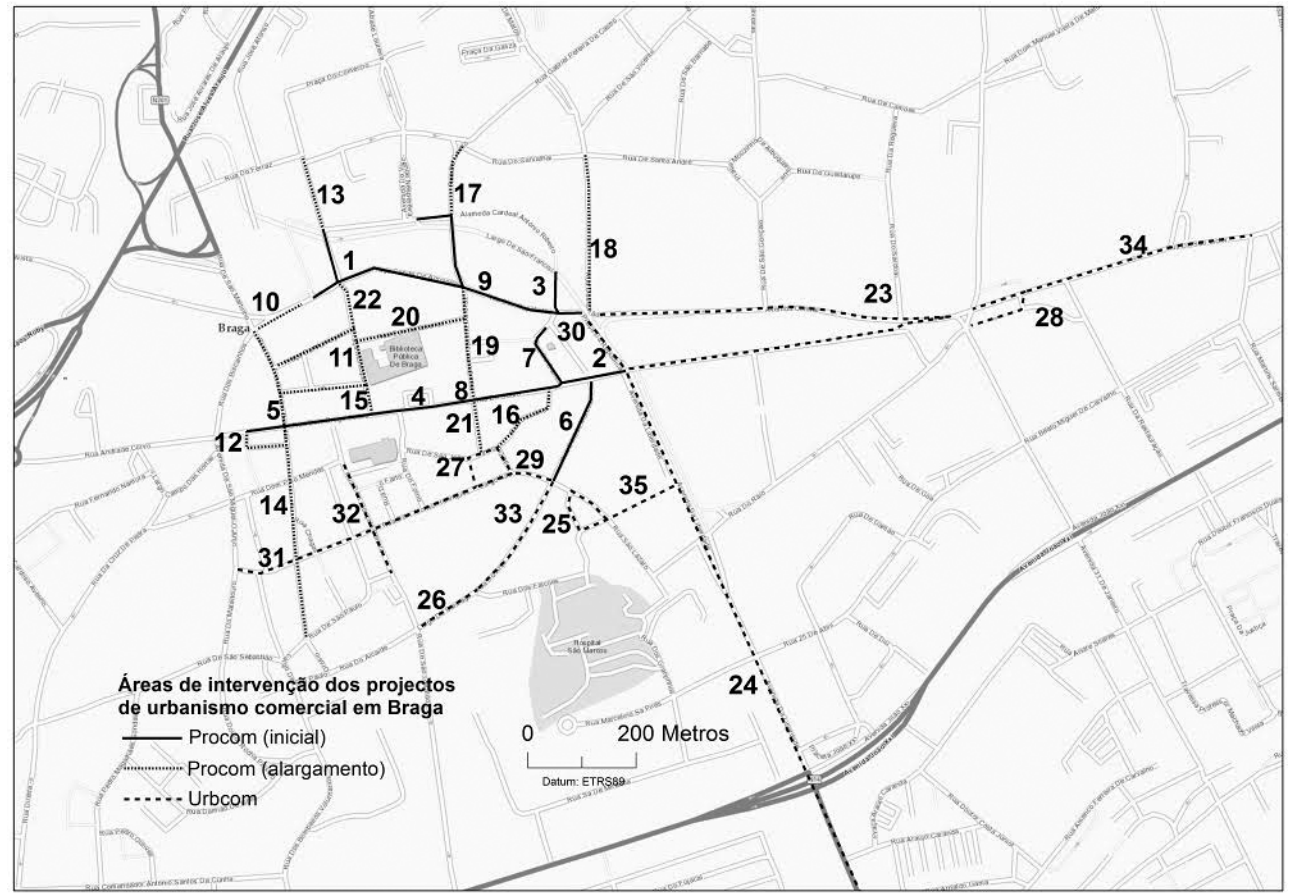

1. Campo da Vinha; 2. Largo Barão S. Martinho; 3. Largo de S. Francisco; 4. Largo do Paço; 5. Rua D. Diogo de Sousa; 6. Rua de S. Marcos; 7. Rua do Castelo; 8. Rua do Souto; 9. Rua dos Capelistas; 10. Praça Conselheiro Torres de Almeida; 11. Praça do Município; 12. Praça Velha; 13. Rua Alferes Ferreira; 14. Rua D. Frei Caetano Brandão; 15. Rua da Misericórdia; 16. Rua de Janes; 17. Rua do Carmo; 18. Rua dos Chãos; 19. Rua Dr. Justino Cruz; 20. Rua Eça de Queirós; 21. Rua Francisco Sanches; 22. Rua Santo António da Praça; 23. Avenida Central; 24. Avenida da Liberdade;

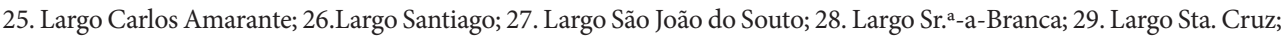
30. Praça da República; 31. Rua D. Afonso Henriques; 32. Rua D. Gonçalo Pereira; 33. Rua do Anjo; 34 . Rua São Victor; 35. Rua Gonçalo Sampaio.

Fig. 2 - Área de intervenção dos projectos Procom e Urbcom na cidade de Braga.

Fig. 2 - Intervention area of Procom and Urbcom projects in Braga.

O estudo global do projecto Urbcom Braga foi realizado em 2005 (Bússola, 2005). As ruas inseridas na área de intervenção deste programa eram significativamente de menor relevância comercial face às que foram incluídas no Procom. De acordo com as entrevis- 
tas realizadas, dois motivos despoletaram a vontade de implantar um projecto Urbcom. O primeiro prende-se com a necessidade da associação comercial facultar aos estabelecimentos que se localizavam fora da área de intervenção do Procom os mesmos mecanismos financeiros para a sua modernização (entrevista 4). Em segundo lugar, como o projecto Procom não tinha englobado a totalidade do centro da cidade, a autarquia podia, desta forma, beneficiar de fundos para concluir o processo de reabilitação daquela área (entrevista 4).

Aderiram ao Procom 169 estabelecimentos de um total de 491 existentes, perfazendo uma taxa de adesão de $34,4 \%$, ainda assim bastante inferior à que tinha sido prevista inicialmente (64\%) (Associação Comercial de Braga, s/data). A adesão ao Urbcom foi significativamente inferior, com apenas 19 estabelecimentos a aderirem a este projecto, num total de 285 existentes na área de intervenção, o que perfaz uma taxa de adesão de 6,7\% (face à previsão de $43 \%$ ). Os erros na obtenção destas taxas devem-se ao optimismo exacerbado que se fez sentir com o projecto Procom (entrevista 3) e com deficiências ao nível da análise da intenção de adesão no Urbcom (Guimarães, 2015). No total foram investidos mais de quinze milhões de euros em ambos os projectos, com clara prevalência dos investimentos realizados no âmbito do projecto Procom (quadro III).

Quadro III - Investimento realizado pelas empresas, autarquia e associação comercial no âmbito dos projectos Procom e Urbcom em Braga.

Table III - Investment of companies, city council and chamber of commerce within Procom and Urbcom projects, in Braga.

\begin{tabular}{lccr}
\hline Investimento realizado por instituição, em $€$ & Procom Braga & Urbcom Braga & \multicolumn{1}{c}{ Total } \\
\hline Empresas & 12427103 & 746876 & 13173979 \\
Autarquias & 1656568 & 163318 & 1819886 \\
Associação comercial & 569582 & 95468 & 665050 \\
\hline Total & 14653253 & 1005662 & 15658915 \\
\hline
\end{tabular}

Fonte: elaboração própria a partir de dados da DGAE (2010)

Durante a realização dos inquéritos e entrevistas, quer aos empresários, quer aos técnicos da Associação Comercial e da Câmara Municipal ficou visível que, de forma mais vincada no Procom, houve um conjunto de empresas que não conseguiu aderir ao projecto por não cumprir com alguns dos requisitos, nomeadamente a obrigatoriedade de possuir capitais próprios e contabilidade organizada. Face a estes requisitos, parte do aparelho comercial de menor dimensão, ainda movido por técnicas de gestão empresarial antiquadas e com reduzida disponibilidade financeira ficou excluída deste projecto, mesmo que localizado no interior da área de intervenção. $\mathrm{O}$ avultado financiamento a fundo perdido apenas era atribuído como reembolso do investimento que teria que ter sido efectuado inicialmente pelos empresários. Os inquiridos também assumiram que os empresários com menor capacidade financeira dificilmente conseguiriam efectuar este investimento inicial e mesmo o recurso a um empréstimo bancário não se assegurava como uma alternativa concretizável. 


\section{Modernização do aparelho comercial}

Tendo sido a componente com maior investimento realizado, em todos os estabelecimentos a modernização do aparelho comercial passou por obras de remodelação física (quadro IV). A aquisição de equipamento informático foi particularmente relevante no Procom, sobretudo porque na altura muitos estabelecimentos ainda não estavam dotados de equipamento informático, aproveitando este projecto para a sua aquisição. Também se privilegiou o uso de técnicas de promoção e marketing, ainda que quase sempre através do recurso a técnicas de vitrinismo. Aproveitou-se a remodelação dos estabelecimentos, em especial no Procom, para se proceder à introdução de novas técnicas de venda, com destaque para o livre-serviço que, até então, pela disposição física das lojas e pelo mobiliário existente, não era fácil de implementar. A diversificação do produto foi elaborada numa lógica de adaptação ao seu cliente-alvo. Os restantes tipos de intervenção são menos relevantes. Apesar de considerado como importante, não foram criados novos postos de trabalho nem foi ajustado o horário de funcionamento dos estabelecimentos, cujo desajustamento com aquele em que os consumidores estavam disponíveis para o consumo era evidente.

Quadro IV - Tipo de intervenção realizada nos estabelecimentos aderentes ao Procom e Urbcom.

Table IV - Intervention made on outlets, within Procom and Urbcom Braga projects.

\begin{tabular}{lcccccc}
\hline \multirow{2}{*}{ Tipo de intervenção } & \multicolumn{2}{c}{ Procom } & \multicolumn{2}{c}{ Urbcom } & \multicolumn{2}{c}{ Total } \\
\cline { 2 - 7 } & $\begin{array}{c}\mathbf{N}^{\mathbf{*}} \\
\text { estab. }\end{array}$ & $\begin{array}{c}\text { \% do } \\
\text { total }\end{array}$ & $\begin{array}{c}\text { No } \\
\text { estab. }\end{array}$ & $\begin{array}{c}\text { \% do } \\
\text { total }\end{array}$ & $\begin{array}{c}\text { No } \\
\text { estab. }\end{array}$ & $\begin{array}{c}\text { \% do } \\
\text { total }\end{array}$ \\
\hline Remodelação do estabelecimento & 61 & 100 & 10 & 100 & 71 & 100 \\
Equipamento informático & 47 & 77 & 8 & 80 & 55 & 77,5 \\
Promoção e marketing & 37 & 60,7 & 5 & 50 & 42 & 59,2 \\
Técnicas de venda & 18 & 29,5 & 2 & 20 & 20 & 28,2 \\
Diversificação do produto & 14 & 23 & 2 & 20 & 16 & 22,5 \\
Qualificação dos recursos humanos & 5 & 8,2 & 1 & 10 & 6 & 8,5 \\
Criação de postos de trabalho & 0 & 0 & 0 & 0 & 0 & 0 \\
Ajuste dos horários de funcionamento & 0 & 0 & 0 & 0 & 0 & 0 \\
Número de estabelecimentos analisados & 61 & 100 & 10 & 100 & 71 & 100 \\
\hline
\end{tabular}

Fonte: Inquéritos realizados aos empresários (2014)

Foi incorporada a análise do contra-factual, isto é, que intervenções teriam sido realizadas nos estabelecimentos caso não tivessem sido executados os dois projectos. Assim, percebe-se que na maioria dos casos as intervenções nos estabelecimentos iam-se realizar, independentemente da adesão aos dois projectos. No Procom, dos 61 estabelecimentos, apenas em 21 não se ia proceder a nenhum investimento, dos quais em 15 casos era por incapacidade económica. Apenas em 6 estabelecimentos o projecto Procom despoletou a necessidade de intervenção (quadro $\mathrm{V}$ ). De facto, durante a realização dos inquéritos percebeu-se que a adesão ao Procom apenas teve como intuito minimizar o investimento que já estava em curso e, alguns casos, mesmo na sua fase final. Não obstante, os 
empresários assumiram que pela obrigatoriedade de cumprir os prazos do projecto, a participação no Procom acelerou o investimento realizado. No projecto Urbcom, ainda que com números mais reduzidos, os dados apontam na mesma direcção.

Quadro V - Contrafactual da intervenção realizada nos estabelecimentos comerciais.

Table V-Counterfactual of intervention carried out in the outlets.

\begin{tabular}{ccccc|ccc|c}
\hline & & \multicolumn{7}{c}{ Se não tivesse recebido apoio, teria feito o investimento? } \\
\cline { 3 - 8 } & & \multicolumn{3}{c}{ SIM } & \multicolumn{4}{c}{ NÃO } \\
\hline \multirow{2}{*}{ Programa } & & $\begin{array}{c}\text { Na } \\
\text { totalidade }\end{array}$ & $\begin{array}{c}\text { De forma } \\
\text { parcial }\end{array}$ & $\begin{array}{c}\text { Total } \\
\text { (SIM) }\end{array}$ & $\begin{array}{c}\text { Incapacidade } \\
\text { económica }\end{array}$ & $\begin{array}{c}\text { Foi o programa } \\
\text { que fomentou a } \\
\text { modernização }\end{array}$ & $\begin{array}{c}\text { Total } \\
\text { (NÃO) }\end{array}$ & Total \\
\hline \multirow{2}{*}{ Procom } & No estab. & 26 & 14 & 40 & 15 & 6 & 21 & 61 \\
\hline \multirow{2}{*}{ Urbcom } & \% do total & 42,6 & 23 & 65,6 & 24,6 & 9,8 & 34,4 & 100 \\
\hline
\end{tabular}

Fonte: Inquéritos realizados aos empresários (2014)

\section{Promoção e animação comercial}

Quer no projecto Procom, quer no Urbcom, as acções de promoção e animação comercial focaram-se em actividades que Stubbs et al. (2002) definiram como Footfall builders, i.e., actividades cujos impactos apenas se fazem sentir durante o período de execução das mesmas, tal como desfiles de moda, exposições temáticas, concertos de música ao vivo, entre outras acções promocionais. Foi exposto pelos empresários que todas as actividades promocionais desenvolvidas apenas se centraram no principal eixo comercial, localizado entre a rua do Souto e o Largo Barão S. Martinho, o que simultaneamente reforçava a sua importância e relegava as restantes ruas para um patamar inferior.

\section{Intervenções urbanísticas}

As intervenções urbanísticas realizadas pela autarquia enquadraram-se na política de reabilitação do centro da cidade que já vinha a ser seguida por esta entidade desde os anos 80. No Procom centrou-se na pedonização da rua Eça de Queirós e na reabilitação na Praça Conde de Agrolongo, vulgo Campo da Vinha (fig. 3 e 4).

Por via do reduzido número de empresas aderentes ao Urbcom, a verba disponível através deste projecto para a intervenção urbanística era limitada, tendo sido utilizada no arranjo de superfície da rua D. Afonso Henriques, cujo investimento ascendeu a 163318 euros. O limitado orçamento para esta rubrica não explica na totalidade o reduzido investimento em acções urbanísticas. De facto, também se confirmou que no período em que o projecto foi executado, a maioria das intervenções no centro da cidade já estavam terminadas e, como tal, também não havia necessidade de intervir (entrevista 3). 


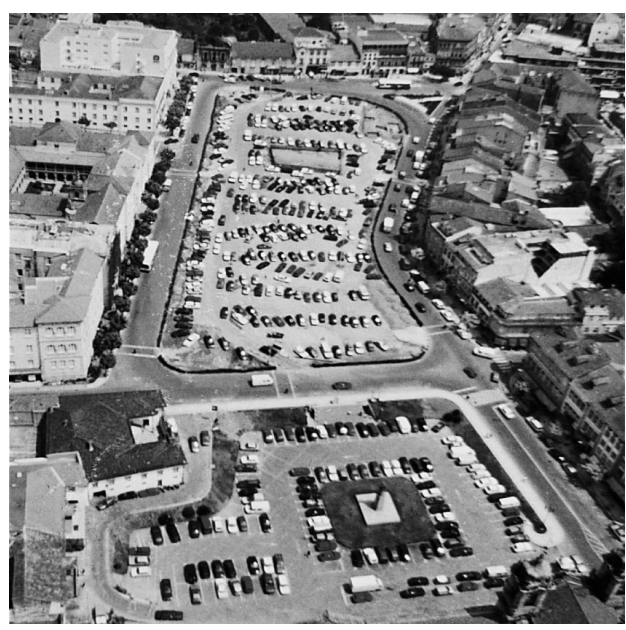

Fig. 3 - Campo da Vinha antes da intervenção urbanística (orientação Este-Oeste). Fig. 3 - Campo da Vinha before urban intervention (East-West orientation).

Fonte: Museu da Imagem/CM Braga

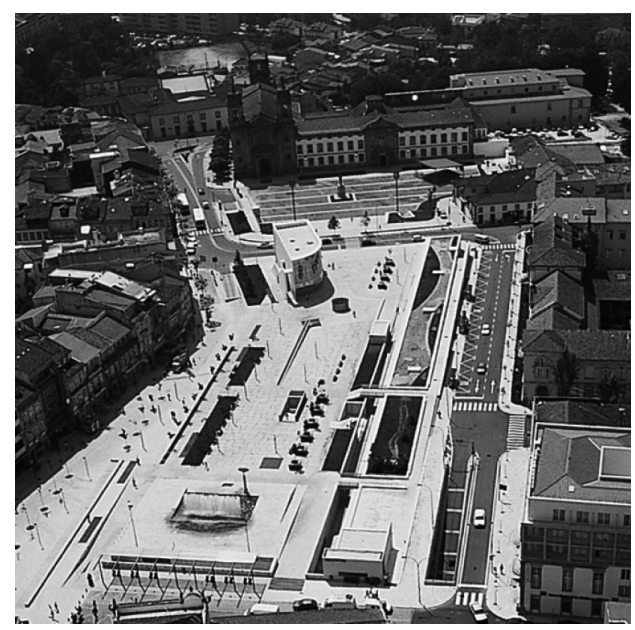

Fig. 4 - Campo da Vinha após a intervenção urbanística (orientação Oeste-Este).

Fig. 4. - Campo da Vinha after urban intervention (West-East orientation).

Fonte: Museu da Imagem/CM Braga

\section{Efeitos da intervenção integrada}

Conforme descrito na secção do material e métodos, apenas iremos apresentar dados sobre os efeitos de intervenção integrada no caso do projecto Procom. Os 44 entrevistados que classificaram os efeitos da intervenção integrada pelo Procom (quadro VI), assumiram que após o projecto a área ficou globalmente mais atractiva e conseguiu-se modernizar o aparelho comercial. No entanto, percebe-se que esta melhoria não foi acompanhada em igual medida por um aumento das vendas, do volume de negócios e do número de clientes, colocando em causa a eficácia do projecto face ao objectivo inicial de reforçar a centralidade desta área.

Quadro VI - Efeitos da intervenção integrada na área de intervenção do Procom Braga, por número de respostas.

Table VI - Effects of integrated intervention in Braga Procom project, in number of responses.

\begin{tabular}{|c|c|c|c|c|c|c|c|c|c|c|c|c|c|}
\hline \multirow[b]{2}{*}{ Efeitos } & \multicolumn{10}{|c|}{ Classificação } & \multirow{2}{*}{$\frac{\grave{z}}{\grave{z}}$} & \multirow{2}{*}{ స్ㅠำ } & \multirow{2}{*}{ 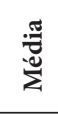 } \\
\hline & $\begin{array}{l}1 \text { (discordo } \\
\text { totalmente) }\end{array}$ & 2 & 3 & 4 & 5 & 6 & 7 & 8 & 9 & $\begin{array}{l}10 \text { (concordo } \\
\text { totalmente) }\end{array}$ & & & \\
\hline A área ficou mais atractiva & - & - & 1 & - & 2 & 4 & 11 & 13 & - & 1 & 12 & 44 & 7,13 \\
\hline Modernizou o aparelho comercial & - & - & - & - & 4 & 4 & 11 & 12 & 1 & - & 12 & 44 & 7,06 \\
\hline $\begin{array}{l}\text { Aumentou as vendas e volume de } \\
\text { negócios }\end{array}$ & - & - & 3 & 7 & 8 & 5 & 6 & 3 & - & - & 12 & 44 & 5,41 \\
\hline Aumentou o número de clientes & - & - & 4 & 7 & 8 & 5 & 5 & 2 & 1 & - & 12 & 44 & 5,31 \\
\hline
\end{tabular}




\section{DISCUSSÃO E CONCLUSÃO}

Neste artigo tivemos o objectivo de analisar o processo de implantação dos projectos especiais de urbanismo comercial Procom e Urbcom de Braga. Para tal, inicialmente debruçamo-nos sobre o planeamento comercial e a forma como se tem reflectido em Portugal. De seguida passamos para a análise dos dois projectos, centrada nas suas especificidades e no que foi realizado ao nível da modernização do aparelho comercial, da reabilitação do espaço público e das acções promocionais.

Retomando o argumento definido anteriormente verificamos que não se confirmou na sua plenitude. De facto, no caso da modernização comercial, comprovamos que na maioria dos casos, a intervenção realizada inseriu-se no processo normal de modernização dos estabelecimentos que os empresários já tinham delineado. Da mesma forma percebemos que os projectos apenas minimizaram os custos que as empresas estavam a ter e, apenas ocasionalmente despoletaram a consciência de que era necessário intervir. Relativamente às intervenções urbanísticas, estas já se encontravam delineadas no processo mais alargado de reabilitação do centro da cidade. A maioria das artérias desta área já tinha sido ou estava a ser intervencionada. No Procom, as excepções verificaram-se no Campo da Vinha e na rua Eça de Queirós, os dois eixos cuja intervenção foi financiada pelo Procom. No Urbcom apenas a rua D. Afonso Henriques foi intervencionada. No entanto, a menor relevância comercial desta rua e a sua localização periférica face à área de intervenção deste projecto faz com que não possa ter produzido impactos positivos relevantes. A componente das actividades de promoção e animação comercial foi a única que de facto não teria decorrido sem a execução dos projectos. Não obstante, não ficou claro de que forma as actividades desenvolvidas poderiam ter provocado impactos positivos na área de intervenção, quer por terem sido temporalmente limitadas, quer por terem sido privilegiadas em demasia algumas artérias comerciais.

Relativamente aos impactos dos projectos, não se conseguiu confirmar que tenham tido alguma durabilidade. Não obstante, a este respeito importa reconhecer a limitação dos vários processos de regeneração urbana. Tal como Hall (2006) apurou este tipo de processo deve ser encarado apenas como um instrumento que deve acompanhar a dinâmica urbana e que aquando do término de um programa é provável que as cidades já se estejam a deparar com novos desafios. Esta questão parece ter sido uma das principais lacunas destes projectos. Ao cristalizar as intervenções, balizando-as no tempo, não reconhece que as áreas urbanas estão muito susceptíveis a mudanças. A análise da intervenção integrada demonstra alguns indícios desta lógica. De facto, os empresários reconheceram que o projecto Procom permitiu melhorar o ambiente e a oferta comercial, sem que isso tenha implicado um reforço da área enquanto destino comercial. Esta incapacidade deve-se ao fato de a área intervencionada ser substancialmente diferente no momento da candidatura ao projecto e no momento em que o projecto se executou e finalmente se concluiu, interna e externamente. No primeiro caso porque sendo o comércio um sector privado e dinâmico, dificilmente se poderia manter estável durante aquele período. Em segundo lugar porque a própria cidade se alterou, deslocando-se para a periferia e abrindo dois centros comerciais de grande dimensão e porque elementos indi- 
rectos como a inauguração da ligação Braga-Porto através da auto-estrada colocou o comércio do centro da cidade sob maior concorrência.

Não obstante, tal como transmitido em diversas reuniões sobre a temática e descrito por um dos entrevistados (entrevista 2), este projecto sempre teve associada uma imagem de sucesso, cuja explicação se deve a diferentes motivos. Em primeiro lugar, porque englobou um grande número de empresas. No entanto, tal como analisamos, em parte dos casos a participação no projecto não foi essencial para a sua modernização. Em segundo lugar, porque foi investido um valor avultado pelas empresas, ainda que, tal como constatamos no quadro IV, o investimento foi demasiado centrado na reabilitação física dos estabelecimentos quando outro tipo de intervenção também era premente. Em terceiro lugar, porque lhe foram atribuídos méritos de todo o processo de reabilitação do centro da cidade, quando na realidade apenas uma praça e uma rua foram intervencionadas com fundos do Procom. Por último, porque aquando da execução deste projecto a concorrência de outras centralidades comerciais ainda estava numa fase inicial e esta área ainda era o principal destino comercial da cidade, situação que se alterou com a abertura de centros comerciais BragaParque e Minho Center, com a expansão urbana de Braga e com a maior acessibilidade ao tecido comercial de maior dimensão que existia na cidade do Porto.

De forma geral, a adesão ao Procom e ao Urbcom parece ter cumprido com a necessidade da associação comercial e da autarquia em intervir naquela que é a área central da cidade. No entanto, a postura adoptada foi de mera resistência interna face às alterações no sector comercial, não levando em consideração a natural evolução da área. A este propósito importa referir que esta resistência apenas se destinou aos empresários cujas empresas já tinham alguma dimensão e cuja vitalidade financeira permitiu fazer face à exigência de capitais próprios, um dos requisitos para participação nos projectos. Desta forma, o desenho dos programas de urbanismo comercial excluiu as empresas mais debilitadas financeiramente e cujos proprietários apresentavam maior oposição à mudança porque mesmo havendo um financiamento significativo a fundo perdido, dificilmente conseguiriam fazer face ao investimento inicial.

Retomando o conceito de eficácia, concluímos que ambos os projectos não foram eficazes porque não conseguiram reforçar a centralidade comercial da área face às ameaças externas que entretanto foram surgindo e porque grande parte do investimento que acabou por ser financiado pelos projectos já o ia ser pelo sector privado. De facto, poderá ter acelerado o processo de modernização do aparelho comercial e até ter fomentado alguns acréscimos na intervenção realizada mas não desencadeou estes processos nem foi essencial para a sua execução.

Em termos de recomendações de política e considerando que programas semelhantes ainda estão em vigor em 2016, devem ser ponderados quais os reais destinatários dos programas. Entendendo que em último caso esta é uma decisão de cariz político, ficou claro que caso se pretenda a modernização de todo o sector comercial, incluindo aqueles apelidados como "históricos", e não apenas os estabelecimentos comerciais que já terão alguma capacidade de se modernizar, novos instrumentos terão de ser aplicados. Num processo relacionado com a duração dos impactos, recomenda-se a introdução de instrumentos mais dinâmicos e permanentes como as estruturas de gestão de centros urbanos 
que, de forma mais ágil e rápida consigam acompanhar a dinâmica urbana e de constante mudança que caracteriza as cidades. Caso contrário, tal como foi possível aprender com estes programas, quando se terminar um projecto, já existe necessidade de executar um novo para fazer face aos desafios que entretanto apareceram.

\section{AGRADECIMENTOS}

A pesquisa para este artigo foi desenvolvida no âmbito de uma Bolsa de Doutoramento financiada pela Fundação para a Ciência e a Tecnologia com a referência SFRH/BD/69355/2010. Fica um agradecimento à Professora Teresa Barata-Salgueiro pela orientação deste doutoramento.

$\mathrm{O}$ autor agradece à equipa editorial da Finisterra e aos revisores os comentários efectuados.

\section{REFERÊNCIAS BIBLIOGRÁFICAS}

Alexander, E. (2006). Evolution and status: where is planning-evaluation today and how did it get here?. In Alexander, E. (Ed.), Evaluation in Planning - evolution and prospects (pp. 3-16). Inglaterra: Ashgate.

Associação Comercial de Braga (ACB) (1995). Urbanismo comercial - projectos especiais - acções de revitalização do comércio no centro histórico de Braga. Braga: Associação comercial de Braga.

Associação Comercial de Braga (ACB) (n.d.). Ficha técnica de candidatura a projecto especial. Braga: Associação comercial de Braga.

Balsas, C. (2007). City centre revitalization in Portugal: A Study of Lisbon and Porto. Journal of Urban Design, 12 (2), 231-259.

Balsas, C. (2002). Urbanismo comercial e parcerias público-privadas. Lisboa: Observatório do comércio.

Balsas, C. (1999). Urbanismo comercial em Portugal e a revitalização do centro das cidades. Lisboa: GEPE.

Balsas, C. (1997). Retail planning in Portugal: an instrument of urban planning. In Ahern, J. \& Machado, J. (Eds.), Environmental challenges in an expanding urban world and the Role of Emerging Information Technologies (pp. 37-48). Lisboa: CNIG.

Barata-Salgueiro, T. (1996). Do comércio à distribuição roteiro de uma mudança. Oeiras: Celta Editores.

Barata-Salgueiro, T. (1995). Retail planning in Portugal. In Davies, R. (Ed.), Retail planning policies in Western Europe (pp. 182-199). Londres: Routledge.

Barata-Salgueiro, T. \& Erkip, F. (2014). Retail planning and urban resilience - an introduction to the special issue. Cities, 36, 107-111.

Bússola (2005). Estudo global Urbcom Braga. Braga: Bússola.
Cachinho, H. (2014). Consumerscapes and the resilience assessment of urban retail systems. Cities, $36,131-144$.

Cachinho, H. (1992). L'urbanisme comercial: un instrument au servisse de l'amenagement des activités commerciales. In Barata-Salgueiro, T. (Ed.), Retailing, Public Policy and Urban Retail Planning (247-260). Lisboa: GECIC.

Câmara municipal de Braga (1997). Candidatura da Câmara Municipal de Braga ao projecto de urbanismo comercial de Braga. Braga: Câmara municipal de Braga.

Colla, E. (2003). France. In Howe, S. (Ed.), Retailing in the European Union: structures, competition and performance (pp. 23-55). Londres: Routledge.

Comissão Europeia (2008). EVALSED: The resource for the evaluation of Socio-Economic Development. Luxembourg: Office for Official Publications of the European Communities.

Davies, R. (2004). Planning policy for retailing. In Reynolds, J., Cuthbertson, C. (Eds.), Retail Strategy, the view from the bridge (pp. 78-95). Reino Unido: Elsevier.

Davies, R. (1995). Preface. In Davies, R. (Ed.), Retail Planning Policies in Western Europe (pp. xiii-xx). Londres: Routledge.

Dawson, J. (1979). The marketing environment. Londres: Croom Helm.

DGAE (2010). Dinamização económica dos centros históricos. Lisboa: DGAE.

Evers, D. (2002). The rise (and fall?) of national retail planning. Tijdschrift voor Economische en Sociale Geografie, 93, 107-113.

Fernandes, J. (2012). Os projectos de urbanismo comercial e a revitalização do centro da cidade. Revista Memória em Rede, 2 (6), 76-89. 
Fernandes, J. (1994). Urbanismo Comercial - a experiência portuguesa. Revista da Faculdade de Letras, I série, X/XI, 105-125.

Fernandes, J. \& Chamusca, P. (2014). Urban policies, planning and retail resilience. Cities, 36, 170-177.

Fernandes, J., Cachinho, H. \& Ribeiro, C. (2000). Comércio tradicional em contexto urbano - dinâmicas de modernização e políticas públicas. Porto: GEDES-UP.

Ferrão, J. (2014). O ordenamento do território como política pública (2a edição). Lisboa: Fundação Calouste Gulbenkian.

Findlay, A. \& Sparks, L. (2009). Literature Review: Policies Adopted to Support a Healthy Retail Sector and Retail Led Regeneration and the Impact of Retail on the Regeneration of Town Centres and Local High Streets. Edimburgo: Scottish Government.

Franzén, M. (2004). Retailing in the Swedish City: The move towards the outskirts. In Franzén, M. \& Halleux, J. (Eds.), European Cities Dynamics Insights on Outskirts (pp. 93-112). Bruxelas: European Science Foundation.

Gorter, C., Nijkamp, P. \& Klamer, P. (2003). The attraction force of out-of-town shopping malls: A case study on the run-fun shopping in the Netherlands. Tijdscrift voor Economische en Sociale Geografie, 94 (2), 219-229.

Greene, F. (2009). Assessing the impact of policy interventions: the influence of evaluation methodology. Environment and Planning C: Government and Policy, 27, 216-29.

Guimarães, P. (2015). O planeamento comercial em Portugal, os projectos especiais de urbanismo comercial. Dissertação de doutoramento em geografia. Lisboa: Universidade de Lisboa.

Guimarães, P. (2014). The prospective impact of new shopping centres on the retail structure of Braga. Bulletin of Geography. Socio-economic Series, 25, 167-180.

Guimarães, P. (2013). The tools for city centre revitalization in Portugal. Journal of Place Management and Development, 6 (1), 52-66.

Guy, C. (2007). Planning for retail development, a critical view of the British experience. Oxon: Routledge.
Guy, C. (1998). Controlling new retail spaces: The impress of planning policies in Western Europe. Urban Studies, 35 (5-6), 953-979.

Hall, T. (2006). Urban Geography (3a edição). Oxon: Routledge.

Howe, S. (2003). United Kingdom. In Howe, S. (Ed.), Retailing in the European Union: structures, competition and performance (pp. 155-187). Londres: Routledge.

Instone, P. \& Roberts, G. (2006). Progress in retail led regeneration: Implications for decision-makers. Journal of Retail and Leisure Property, 5, 148-161.

Karrholm, M. \& Nylund, K. (2011). Escalating Consumption and Spatial Planning: Notes on the Evolution of Swedish Retail Spaces. European Planning Studies, 19 (6), 1043-1059.

Mérenne-Schoumaker, B. \& Browet, A. (1988). Localisation du magasin, Guide pratique. Bruxelas: Comite Belge de la distribution.

Pereira, M., Teixeira, J. A. \& Biaggio, S. (2002). Regulação do equipamento comercial nos países da União Europeia. Lisboa: Gabinete de Estudos e Prospectiva Económica.

Roberts, P. (2000). The evolution, definition and purpose of urban regeneration. In Roberts, P. \& Sykes, H. (Eds.), Urban Regeneration - a handbook (pp. 9-36). Reino Unido: Sage publications.

Sorensen, M. (2004). Retail Development and Planning Policy change in Denmark. Planning, Pratice \& Research, 19, 219-231.

Spierings, B. (2006). The return of regulation in the shopping landscape? Reflecting on the persistent power of city centre preservation within shifting retail planning ideologies. Tijdschrift voor Economische en Sociale Geografie, 97, 602-609.

Stubbs, B., Warnaby, G. \& Medway, D. (2002). Marketing at the public/private sector interface; town centre management schemes in the south of England. Cities, 19 (5), 317-326.

Thomas, C. \& Bromley, R. (2003). Retail revitalization and small town centres: the contribution of shopping linkages. Applied Geography, 23, 47-71.

Tyler, P., Warnock, C., Provins, A. \& Lanz, B. (2013). Valuing the Benefits of Urban Regeneration. Urban Studies, 50 (1), 169-190.

A Lei Royer foi um diploma legal implementado em França, em 1973, com o objectivo de controlar a expansão dos estabelecimentos comerciais de maior dimensão, em especial os hipermercados. As políticas $P D V$ e $G D V$ são instrumentos do planeamento comercial Holandês que regulam a localização dos estabelecimentos comerciais. A política do Town Centre First no Reino Unido está relacionada com a limitação da abertura de estabelecimentos e conjuntos comerciais na periferia das cidades e com uma orientação pró-activa de defesa da vitalidade e viabilidade do centro das cidades. As estruturas de Town Centre Management e Business Improvement Districts descritas neste artigo são instrumentos que reflectem esta orientação. 